\title{
TRUST IN PREPARATION OF UNIVERSITY-INDUSTRY (UI)-COLLABORATION: OUTCOMES FROM A COURSE WITH FOCUS ON DEVELOPING BUSINESSLIKE CAPABILITIES
}

\author{
Håkan Perzon, Luleå University of Technology, Sweden
}

\begin{abstract}
This paper presents outcomes from a course with focus on developing businesslike capabilities among undergraduate students. The purpose is to explore the need of trust in preparations of UI-collaboration and how outcomes are influencing trust in an education context. Findings indicate that word of mouth is essential to create needed trust. The amount of human resources students represent is found to be an important "qualifier", while created trust is the "order winner" in the establishment of UI-collaboration.
\end{abstract}

\section{INTRODUCTION}

Bjerregaard, (2009) has reported that partners in university-industry (UI) collaboration choose to pursue difference short- or long-term strategies to optimize the process and outcome of the collaboration. Due to Bjerrgaard's focus on researchers "strategy" for industry collaboration, one implication is that "actors with prior UI collaborative experience may successfully consider the collaboration in terms of its immediate R\&D goals."(ibid, p 173). It is also suggested more research on longitudinal social dynamic interactions between collaborating UI partners during collaboration. While R\&D collaboration has a dual nature (Davenport et al 1999) it is of interest to explore if there are similar conditions in collaboration in an education context characterised by firms, undergraduate students, and teachers involvement.

The foundation for this paper is a holistic view of a company from a business perspective focus on business capabilities development, i.e. problem solving and development of analytical capabilities, among undergraduate students in real life contexts (Bonnet et al. 2006, Ehab and Lashine 2003, Jones 2007). While education can be viewed as service (Lovelock 1983), especially in a UI-collaboration context and trust is of importance in service industries (Kantsperger and Kunz 2010,) it is of interest exploring $t$ the role of trust in an education context. Dagger \& O'Brian (2010) has in their studies regarding consumers experience found indications on how trust varies as a function of customers experience in a relationship.

It is reasonable to assume that large enterprises have established UI-collaboration strategies. While this paper focusing small firms, the purpose with this embedded single case study, using an inductive and longitudinal approach, is to explore the need of trust in preparations of UI-collaboration and how collaboration outcomes are influencing trust in an education context characterised by students, teachers, and firms.

\section{METHOD}

During three UI-collaboration occasions (2008 - mechanical industry, 2009 - carpentry industry, 2010 - electronic industry) the course have had the purpose to integrate totally 124 student's prior knowledge (sixth semester) from disciplines within business administration by progression in teams through all categories of learning (Chroneer et al. 2009), in short term collaboration (8 weeks) with clusters of firms. The disciplines are marketing, organization, accounting, quality, and logistics. The unit of analyses includes several levels i.e., the annual student group, the student project teams each year, the individual student each year, and managers of firms.

Data collection is triangulated through multiple sources, i.e. through observations of seminars and group discussions, interviews with students' project teams as well as individual students, project documentation including project and progress reports, examination documentation, reflections among the teachers, and interviews with managers.

Weekly reports, individual student reflections, and group discussions from students have been analysed regarding their view on collaboration with real firms, their efforts regarding learning, and their view on their progress regarding applying knowledge from prior courses and link new information to their existing knowledge.

Managers from the firms have been interviewed regarding their expectations on the collaboration and later on about their experience from the collaboration. They have also been interviewed about previous experience from UI-collaboration. The managers have been mapped in patterns of relationship and interviewed about their expressions of their experiences from the collaboration and what made them accept the offered collaboration. 


\section{THE COURSE}

The case explored on is a course for engineering students that integrate knowledge from disciplines within business administration. Students are supposed to apply and integrate prior experiences/knowledge, e.g. from courses taken as well as work experiences, with new information needed for preparing solutions of a firms real life problems. Three lecturers has taken a coaching and guiding role rather than a traditional lecturing role. The course focuses on problem solving and development of analytical capabilities in a business context, i.e. businesslike capabilities. The course is based on five aims supposed to guide the students in their learning process. After the completed course the students should be able to; 1) Problematize and identify problems related to a company's comprehensive situation. 2) Assess information needed for solving the identified problem. 3) Perform analyses; anticipate consequences (scenarios) of the identified problem. 4) Develop suggestions based on different scenarios and thereby provide recommendations on problem solutions. 5) Communicate the recommendations to stakeholders both in verbal and written form.

The course is foremost based on seminars, students' project work in teams, and student - lecturers guiding occasions. The course starts with a presentation of company facts; background, current situation and potential company problems to deal with by managers of the real life firms. The presentation does not include strategies and plans for the future. Seminar 1 includes a presentation of problems identified, information needed and a plan for the project. Seminar 2 includes presentation of a partial report of the assignments and the work in progress. The first two seminars also include oppositions on and discussions of the work. Seminar 3 includes a final presentation of recommendations where students act as consultants in front of the real life company board. The seminars are complemented with guidance sessions before each seminar where students and lecturers discuss and reflect on the individual projects.

Examination of the course includes both individual and group project activities. The group examination consists of 1) written project reports, 2) weekly progress reports of the projects, 3) verbal presentations and 4) opposition on projects. The individual examination consists of 1) written assignments where students are supposed to elaborate on their problematization, reflection, integration, and application of business administration theories and models, 2) active participation in seminars, 3) individual written progress report of both own learning and project progress. The course aims and its design is related to a view on the learning process as shown in figure 1.

\section{TRUST IN PREPARATION OF UI-COLLABORATION}

While education in an UI-collaboration context can be viewed as occasions of learning as well as service, it's obvious that everyone in an UI-collaboration (firms, students, and teachers) might not share similar perspectives on education programs, particular on a "hands-on" course. "Hands-on" is defined as student training by using student's prior knowledge and new information in real life cases where the students have to elaborate on derived problems and needed information. In Bjerregaard (2009) it is indicated that differences in goals and culture can be disturbing for establishment of collaboration. In R\&D collaboration firms goals was related to delivery of products while researchers' goals was related to publishing. A similar difference in an education context can be assumed to appear regarding learning and business development.

The preparation consists of negotiations with potential firms for collaboration about how they can influence the design of the student assignments based on firm's requirements regarding expected outcomes/recommendations in addition to the universities requirements regarding learning outcomes. The preparation aims to establish collaboration with a cluster of firms accepting the university's requirements: 1) to present the firms background and current situation but not to assign detailed tasks, 2) to be able to support students with answers on their questions and provide requested information, 3) to attend student's final presentation, and comment on their suggestions regarding identified problems in firms. The firms are allowed to decide about the questions which are possible to be answered and the information which is available. Restriction in firms' ability to assign detailed tasks is caused by the course aims.

The amount of experience from UI-collaboration among the firms has a variation from several occasions to very few. While firms experienced in UI-collaboration are used to assign detailed tasks, selling is needed to make the firm's accept the collaboration. The offering is the amount of human resources the students represent in combination with restrictions regarding firms' presentation of detailed tasks. 


\section{FINDINGS}

The purpose of this paper has been to explore the need of trust in preparation of UI-collaboration. The results indicate that word of mouth is essential to create needed trust among proposed cluster of firms. While dissemination of positive word of mouth (Dagger \& O'Brian, 2010) is based on firm's satisfaction in previous experiences, the outcome of the students' efforts is affecting that experience. The result indicates that students put more effort in their work when the course design is based on collaboration with firms. While the course content is influenced by the students own problem identification among the clustered firms, there is indications showing that students feel more responsible to their delivery of outcome.

The result indicates also that the amount of human resources the students represent is an important "qualifier" when creating interest among potential firms for collaborating, while created trust is the "order winner" in the establishment of collaboration, especially when firms possibilities in assigning detailed tasks is restricted. One manager's expression supports the qualifier dimension by "I am satisfied if just a few percent of the students' 20000 hours of work is of high quality". The need of trust for order winning seems to be related to relations among managers and their expressions of what they have told other managers about their experiences. Established, trustful relations between firms with experience from collaboration in an occasion of a hands-on course, and inexperienced firms, has made acceptance of proposed collaboration with, inexperienced firms easier.

\section{REFERENCES}

Biggs J. (2004) Teaching for Quality Learning at University, 2nd ed, Open University Press

Bjerregaard T.(2009) University-industry collaboration strategies: a micro level perspective European Journal of Innovation Management, Vol 12, No 2, pp. 161-176

Bonnet, H., Quist, J., Hoogwarwe, D., Spaans, J., Wehrmann, C (2006), Teaching sustainable entrepreneurship to engineering students: the case of Delft University of Technology, European Journal of Engineering Education, Vol. 31, No. 2 pp 155167.

Chroneer D., Johansson J., Perzon H. (2009), Value Creation in Learning. Experiences and Outcomes from Engineering Education, In. Pia Lappalainen (Ed) Continuing Engineering Education (pp.91-99), SEFI and TKK Dipoli..

Dagger T.S. \& O’Brien T. K. (2010). Does experience matter? Differences in relationship benefits, satisfaction, trust, commitment and loyalty for novice and experienced service users, European Journal of Marketing. Vol. 44 No. 9/10 pp.1528-1552

Davenport, S., Davies, J. and Grimes, C. (1999), Collaborative research programmes: Building trust from difference, Technovation, Vol. 19, pp. 31-40.

Ehab, K.A. \& Lashine, S.H. (2003) Accounting knowledge and skills and the challenges of a global business environment, Managerial Finance, Vol. 29, No. 7, pp. 3-16.

Jones, C. (2007) Creating the reasonable adventurer: the co-evolution of student and learning environment, Journal of Small Business and Enterprise Development, Vol. 14 No.2, pp. 228-240.

Kantsperger R., Kunz W. H.(2010) Consumer trust in service companies: a multiple mediating analysis Managing Service Quality Vol. 20 No. 1 pp 4-25

Lovelock Christopher H. (1983) Classifying Services to Gain Strategic Marketing Insights, Journal of Marketing. Vol. 47, (Summer), pp 9-20 


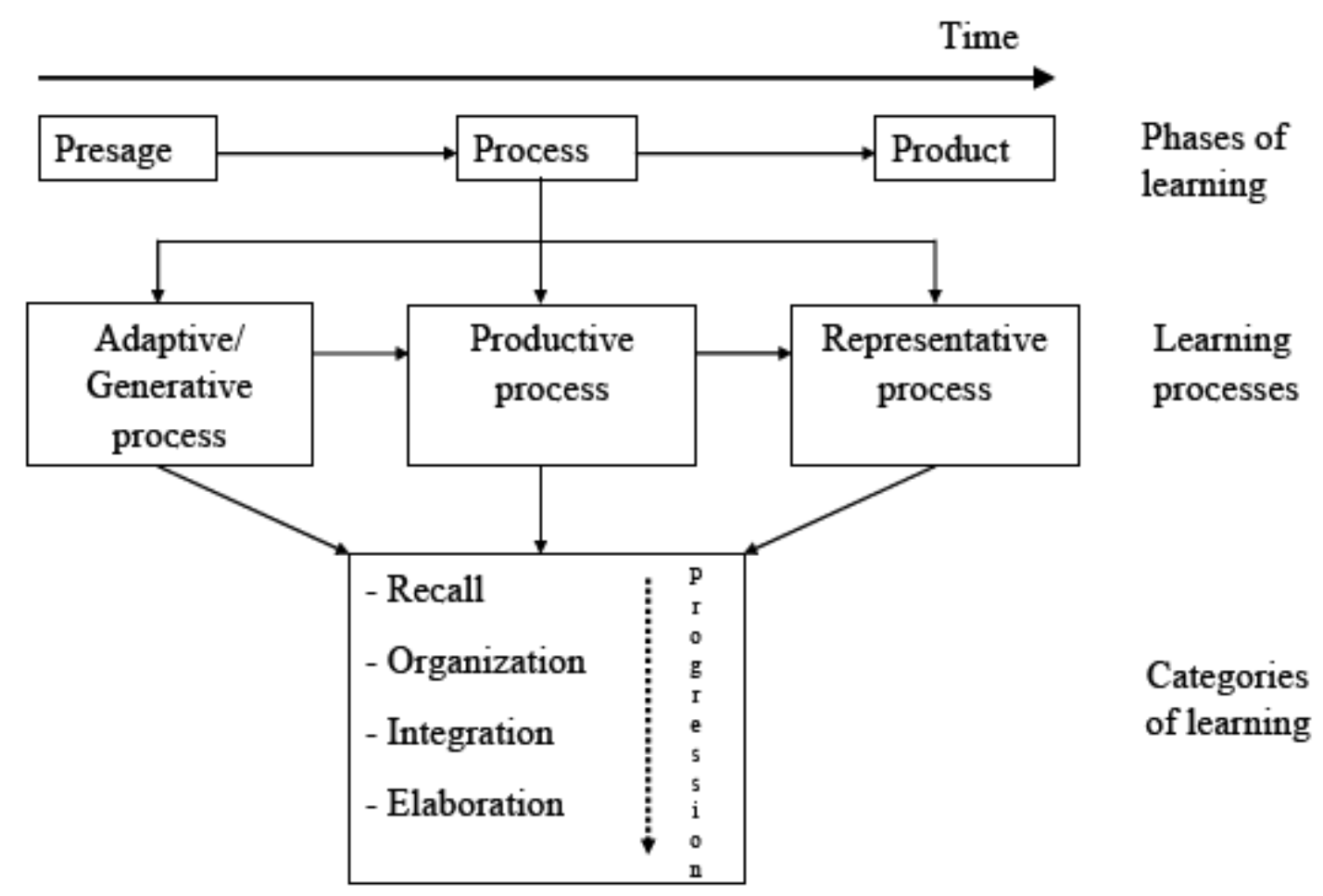

Figure 1: The learning process. Learning refers to three main phases 1) presage (input), 2) process and 3) product (output), (Biggs 2004). The learning process is further explored through three subcategories of learning processes, i.e. the 1) adaptive and generative learning 2) productive and 3) representative. The learning processes are further illustrated through four main categories of learning; 1) recall, 2) organization, 3) integration and 4) elaboration. The four categories describe the progress of learning from a lower level of learning (adaptive learning) to high level of learning (generative learning) (Chroneer D., Johansson J., Perzon H. 2009, p 93) 